doi:10.4149/neo_2013_029

\title{
Invasive neuroendocrine carcinoma of the breast: A prognostic research of 107 Chinese patients
}

\author{
Y. ZHANG ${ }^{1}$, Z. CHEN ${ }^{1}$, Y. BAO ${ }^{1}$, Z. DU ${ }^{1}$, Q. $\mathrm{LI}^{1}, \mathrm{Y}^{2} \mathrm{ZHAO}^{1}$, F. TANG ${ }^{1,2, *}$ \\ ${ }^{1}$ Department of Pathology, Huashan Hospital, Fudan University, Shanghai, 200040, China; ${ }^{2}$ Department of Pathology, Huashan Hospital, Jing'an \\ District Centre Hospital, Fudan University, Shanghai, China
}

*Correspondence: tangfeng519@yahoo.com

Received May 20, 2012/ Accepted October 1, 2012

\begin{abstract}
Neuroendocrine carcinoma (NEC) of the breast, a distinct type of mammary carcinoma whose terminology was not proposed until 2003, has not been well recognized or studied. The aim of our study is to evaluate the clinicopathological features and outcomes of this type of tumor. We conducted a comparative study on 107 NEC patients and 475 invasive ductal carcinoma, not otherwise specified(IDC, NOS) patients from the Department of Pathology, Huashan Hospital, Fudan University, to determine the demographic, pathological, and clinical features at presentation, along with patient outcomes and prognostic factors. With an older age at presentation, NECs are more likely to be estrogen receptor(ER)/ progesterone receptor (PR) positive and human epidermal growth factor receptor 2 (HER-2) negative, and have a higher propensity for local recurrence and poorer overall survival(OS). Higher T classification, $\mathrm{M}$ classification, TNM stage, the expression of Ki67, and the absence of PR expression are prognostically of poorer OS and distant recurrence-free survival(DRFS). Distant metastasis is also a dependent prognostic factor. NEC of the breast is a distinct type of neoplasm with higher malignancy. Novel therapies such as the endocrine therapy should be explored and studies with larger case number and longer follow-up will be needed.
\end{abstract}

Key words: neuroendocrine, breast cancer, prognosis

Primary invasive breast carcinoma with neuroendocrine (NE) differentiation is an uncommon tumor, which accounts for 2-5\% in all breast malignancies. In 1963 Feyrter and Hartmann described a carcinoid growth pattern in some cases of invasive breast carcinoma [1]. Since then it had been sporadically reported $[2,3,4,5]$. Immunohistochemical staining for the neuroendocrine markers synaptophysin, chromogranin and neuron-specific enolase (NSE) subsequently became the standard method of confirming neuroendocrine differentiation. In 2003, WHO histologic classification of tumors of the breast and female genital organs defined it as mammary carcinoma with more than $50 \%$ of neoplastic cells expressing NE markers by immunohistochemistry[6].

Most of the studies on NEC of the breast were conducted prior to the $2003 \mathrm{WHO}$ criteria $[7,8,9,28]$. Before that time, there was no consensus on whether the diagnosis of NEC of the breast should be based on morphology alone or in conjunction with immunohistochemical studies or the amount of NE differentiation required for the diagnosis. Due to lack of a precise definition of mammary NEC, it was difficult to compare the clinicopathological features and outcome data between mammary NEC and invasive ductal carcinoma, not otherwise specified (IDC, NOS). Since 2003, when the WHO criteria demanded immunohistochemical confirmation of neuroendocrine differentiation in $>50 \%$ of NEC tumor cells, limited studies have been conducted $[6,10,11,25,27]$.

In this paper, we carried out a comparative study on 116 Chinese NEC patients who were treated from 2000 to 2011 at the Department of Pathology, Huashan Hospital, Fudan University (Shanghai, China). Most of the patients were initially diagnosed as IDC,NOS. Immunochemistry on NE markers was performed retrospectively to confirm NEC. Clinical treatment and follow-up information were available in 107 of the 116. We show that NEC is a malignant tumor with a higher tendency for local recurrence and a poorer overall survival than IDC, NOS. Therefore, further investigations on the clinicalpathological features, novel treatments, and prognosisinfluencing factors are of high significance. 


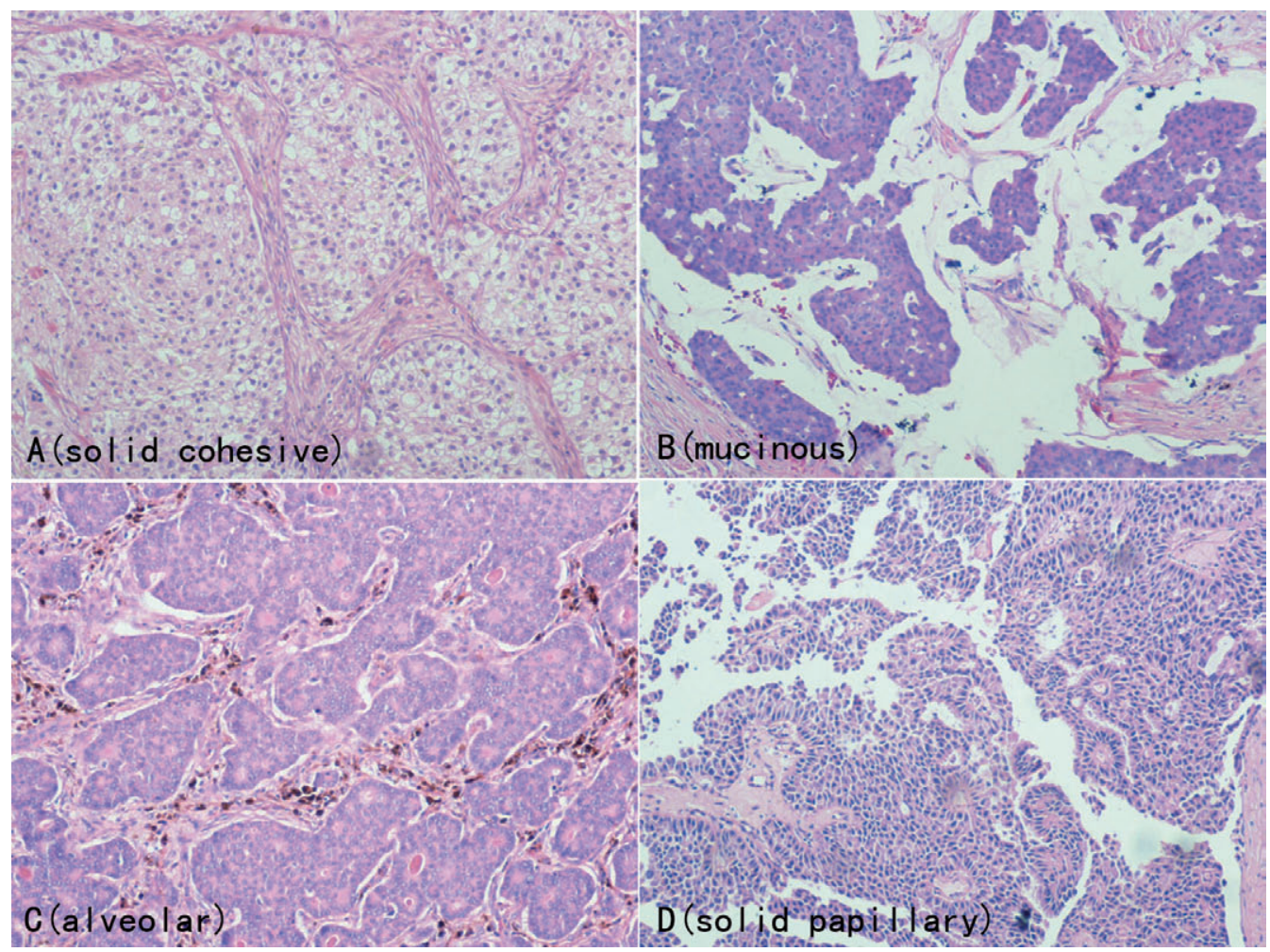

Figure 1. Photomicrographs of NEC subtypes of the breast, solid cohesive(A), mucinous(B), alveolar(C), and solid papillary(D).

\section{Materials and methods}

Study group. A total of 116 NEC patients were identified from 2000 to 2011 at the Department of Pathology, Huashan Hospital, Fudan University. 107 of them have complete clinicalpathological information and outcome data. All 107 cases were confirmed to be NEC by immunohistochemical staining for NE markers (ie, $>50 \%$ of the invasive tumor cells expressing synaptophysin(Sy) and/or chromogranin A(CgA) based on the 2003 WHO criteria). Photomicrographs of NEC of the breast and immunohistochemical results are shown in Fig1 and Fig2. Demographics, clinicopathological factors, treatments and outcome data were retrospectively reviewed.

Cases that fulfill the current $2003 \mathrm{WHO}$ diagnostic criteria were included in this group: (1) with histologic features similar to NE tumors in the gastrointestinal tract and lung and (2) with more than $50 \%$ of tumor cells expressing NE markers by immunohistochemistry. Cases are excluded if: (1) $<50 \%$ tumor cells expressed NE markers, (2) metastatic NECs from other organs based on clinical medical records and pathological features(since we basically focused on primary neuroendocrine carcinoma of the breast) (3) tumor fulfilled the criteria of a small cell carcinoma(since the clinicopathologic features and poor clinical outcome of small cell carcinoma have been well documented $[12,13])$.
All 107 cases were Chinese and female, and were treated at Huashan Hospital, Fudan University from 2000 to 2011. Four (3.7\%) patients were first diagnosed with invasive breast carcinoma before 2003 WHO NEC diagnostic criteria, the remaining 103(96.3\%) in or after 2003. Diagnoses of those 4 patients before 2003 were retrospectively rendered based on the pathological review of their materials and immunohistochemical staining on NE markers(ie, Sy and CgA).

Comparative group. A total of 602 patients with IDC,NOS were treated at Huashan Hospital, Fudan University between January 1999 and December 2003. 475 cases with complete follow-up information were used as a control cohort to compare the clinicopathological features and outcome with the NEC group. All cases were confirmed by thorough review of medical records, hematoxylin and eosin-stained histological and immunohistochemical slides. The remaining 127 patients were excluded because we couldn't obtain complete follow-up information from our medical records.

Histopathologic examination. The histopathology of each case was re-reviewed and the diagnoses were confirmed by positive immunohistochemical staining for $\mathrm{Sy}(27 \mathrm{G} 12$, DAKO, Shanghai) and/or CgA (LK2H101+PHE5,DAKO, Shanghai) in $>50 \%$ of the invasive tumor cells. Immunohistochemical studies were manually performed on one representative block, using the avidin-biotin complex $(\mathrm{ABC})$ horseradish-peroxidase method. 


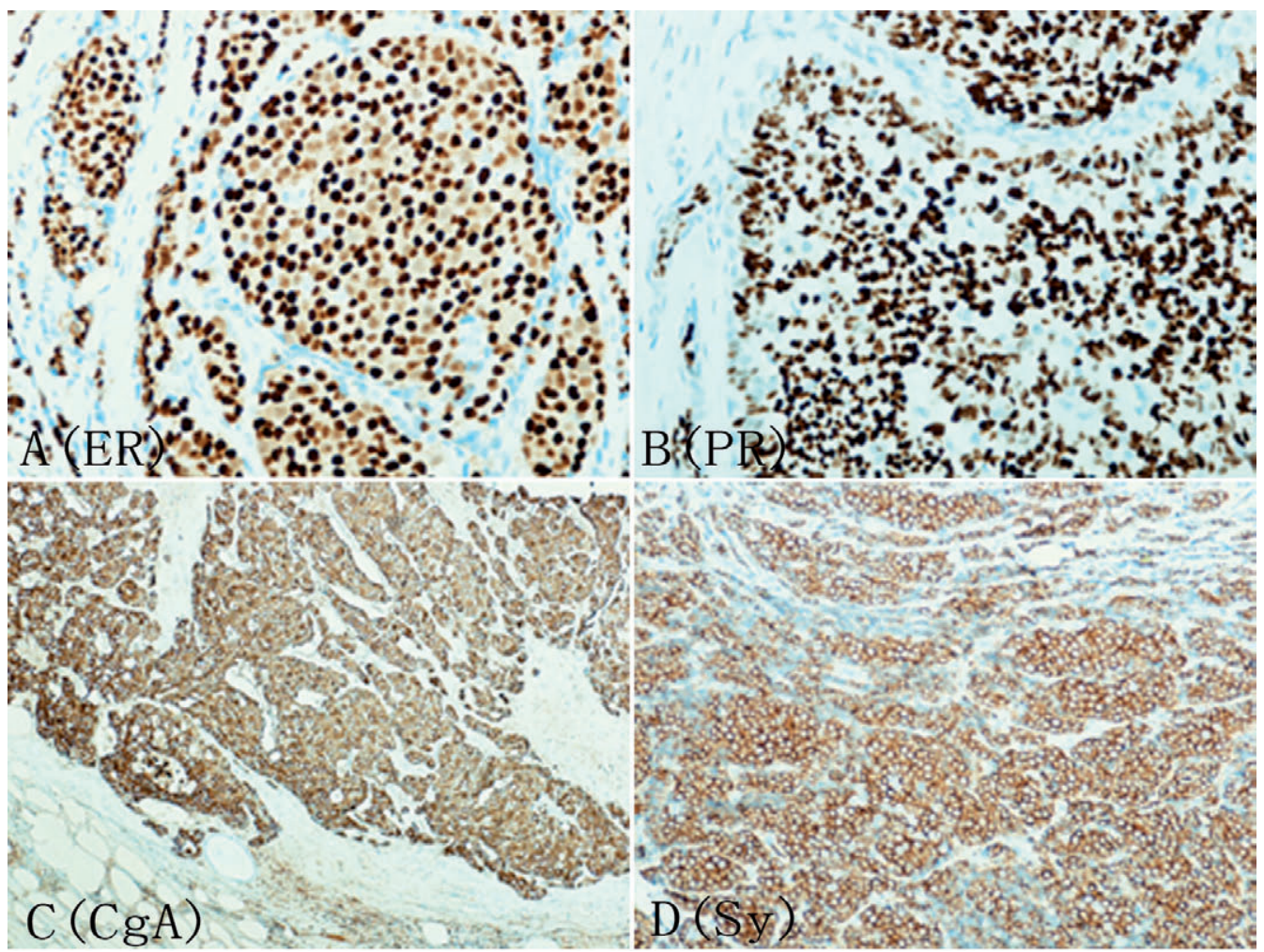

Figure 2. Immunohistochemistry of NEC of the breast showing positivity for estrogen receptor (A), progesterone receptor (B), chromogranin (C) and synaptophysin (D).

Primary antibodies against the following antigens were applied according to the manufacturer's guidelines (Dako): ER, PR, HER-2, Ki67, Sy, and CgA. ER/PR/HER-2 results were obtained from the original histo-pathology reports. Nuclear staining in $10 \%$ of tumor cells was the threshold for ER and PR positivity. HER-2 positivity was referred to as $+++(>30 \%$ tumour cells were strongly positive). Tumors was determined as having low $(<14 \%$ Ki67 positive cells) and high ( $>14 \%$ Ki67 positive cells) proliferative activity [14]. The same methods and scoring system were used in NEC and IDC,NOS group. The antibodies used in this study were listed in Table 1.

Statistical analysis. Descriptive statistics were calculated for demographic and clinicopathological factors. Differences in these factors between NEC and IDC, NOS of the breast were compared using chi-square or Fisher exact test, where appropriate.

Survival data were analyzed based on 3 endpoints from the time of diagnosis. Overall survival was measured from the date of diagnosis to the time to death. Local recurrence-free survival (LRFS) was defined as the time to local disease recurrence or death as a result of NEC or IDC NOS. Likewise, distant recurrence-free survival (DRFS) referred to as the time to distant disease recurrence or death from NEC or IDC NOS. Survival curves were constructed using the Kaplan-Meier method, and differences between curves were analyzed using the Log-rank
Table1. The list of antibodies.

\begin{tabular}{lccc}
\hline Antibody(clone) & Company & Antigen Retrieval & Dilution \\
\hline Sy(27G12) & DAKO & Citrate & $1: 100$ \\
CgA(LK2H101+PHE5) & DAKO & Citrate & $1: 100$ \\
ER(1D5) & DAKO & Citrate & $1: 100$ \\
PR(1A6) & DAKO & Citrate & $1: 100$ \\
HER-2(e2-4001+3B5) & DAKO & Citrate & $1: 100$ \\
Ki67(SP6) & DAKO & Citrate & $1: 100$ \\
\hline
\end{tabular}

test. Multivariate analysis for survival time was performed using the Cox proportional hazards model. Qualitative variables were analyzed using the Pearson $\mathrm{X}^{2}$ test or the Fisher's exact test, when appropriate. All calculations were performed with Stata software (Stata/SE 15.0 for Windows; StataCorp, College Station, Tex).Two-tailed P values.05 were considered statistically significant.

Results

Clinicopathological features and outcomes of IDC,NOS and NEC of the breast

Clinical presentation at diagnosis. The clinicopathological characteristics of the 107 patients with NEC of the breast and 

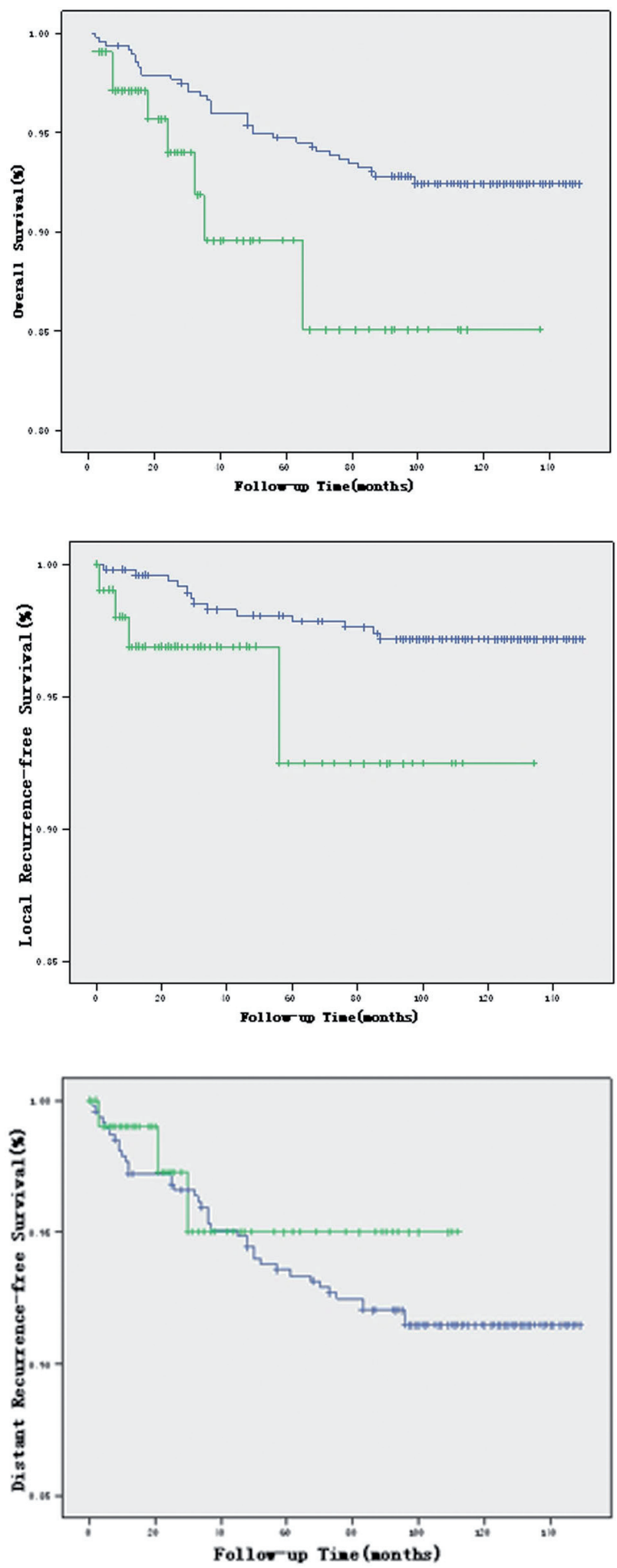

Figure 3. Overall survival, local recurrence-free survival and distant recurrence-free survival comparison between 107 patients with neuroendocrine carcinoma and 475 controls with invasive ductal carcinoma, not otherwise specified are shown. the group of 475 patients with IDC,NOS from Huashan Hospital, Fudan University are summarized in Table 2.

Age at diagnosis. The mean age of patients at presentation in NEC group was 65 years (range, 25-95 years; median, 64years). Patients with NEC were significantly older $(\mathrm{P}<.0001)$ than the 475 patients with IDC, NOS (range, 28-95 years, median, 54 years).

Menstrual status. 78 of 107 ( $72.90 \%)$ patients with NEC of the breast were postmenopausal, 29(27.10\%)were premenopausal, while in the IDC, NOS group, 227 (47.79\%) were postmenopausal and $248(52,21 \%)$ premenopausal. There were significantly more postmenopausal patients in the NEC group than in the IDC, NOS group $(\mathrm{P}<0.0001)$. This was consistent with the higher presenting age at diagnosis in NEC patients.

\section{Stage at diagnosis}

Tumor stage (Tumor size.) The diameter of tumors ranged from 0.8 to $5.0 \mathrm{~cm}$ in the NEC group, and 0.6 to $8.0 \mathrm{~cm}$ in the IDC, NOS group. Most tumors in patients with NEC were stage T2 (54, 50.47\%), compared with a large number of tumors in IDC, NOS patients being stage T1 $(281,59.16 \%)$. Tumor stage in NEC patients were significantly higher than that in IDC, NOS patients $(\mathrm{P}=0.014)$.

Regional lymph node metastasis (N classification). Among the 107 NEC patients, 81 (75.70\%) were stage N0, 18 (16.82\%) were stage N1, $2(1.87 \%)$ were stage $\mathrm{N} 2$, and $6(5.61 \%)$ were stage N3. N classification of NEC tumors was significantly lower than that in IDC, NOS $(\mathrm{P}=0.026)$

Distant metastasis (M classification.) There was no obvious difference between the two cohorts as to distant metastasis in tumors.

AJCC TNM stage. Based on the AJCC staging system (version6) of tumors [15], 39 (36.45\%) NEC patients were stage I, 59 (55.14\%) were stage II, 6 (5.61\%) were stage III, and 3 $(2.80 \%)$ were stage IV. There were no significant differences in TNM stage between the NEC and IDC, NOS groups.

Mitotic figure. In the NEC cohort, 77 (71.96\%) patients had less than 10 mitosis per high power field, while in the IDC, NOS group, the number was 290 (61.05\%). There were statistical differences in mitotic figure between the two groups $(\mathrm{P}=0.036)$

Receptor status. Most NECs of the breast were ER/PR positive and HER-2 negative. 101 (94.39\%) patients were ER positive and 91 (85.05\%) were PR positive. ER/PR expression was significantly higher in NEC patients than that in IDC, NOS patients $(\mathrm{P}<0.0001)$. In NEC patients, $97.20 \%$ were HER-2 negative, and only $2.80 \%$ were HER-2 positive. HER-2 expression was significantly lower in NEC patients than that in IDC, NOS patients $(\mathrm{P}<0.0001)$.

Clinical outcomes. The median follow-up for patients with NEC of the breast was 27 months (range, 3 to 134 months), and that with IDC, NOS was 100 months (range, 92 to 149 months). Clinical outcomes for NEC and IDC,NOS can be seen in Fig 2.

Overall survival. Overall survival rate was lower in NEC patients (85.1\%) than in IDC, NOS patients (92.4\%). Log-rank 
Table 2. Demographic and Clinical Features of the NEC Cohort $(n=107)$ Compared With the Invasive Mammary Carcinoma ( $n=475)$ Cohort at Clinical Presentation

\begin{tabular}{|c|c|c|c|c|c|}
\hline Features & $\begin{array}{l}\text { NEC cohort } \\
N=107 \\
\quad \text { No. of patients }\end{array}$ & $\%$ & $\begin{array}{l}\text { IDC,NOS cohort } \\
N=475 \\
\quad \text { No. of patients }\end{array}$ & $\%$ & $\mathbf{P}$ \\
\hline Age & & & & & $<.0001$ \\
\hline$\leqq 60$ & 46 & 42.99 & 332 & 69.89 & \\
\hline$>60$ & 61 & 57.01 & 143 & 30.11 & \\
\hline Menopausal status & & & & & $<.0001$ \\
\hline Premenopausal & 29 & 27.10 & 248 & 52.21 & \\
\hline Postmenopausal & 78 & 72.90 & 227 & 47.79 & \\
\hline Tumor stage & & & & & .014 \\
\hline $\mathrm{T} 1(\leqq 2 \mathrm{~cm})$ & 48 & 44.86 & 281 & 59.16 & \\
\hline $\mathrm{T} 2(2-5 \mathrm{~cm})$ & 54 & 50.47 & 169 & 35.58 & \\
\hline $\mathrm{T} 3(\geqq 5 \mathrm{~cm})$ & 5 & 4.67 & 22 & 4.63 & \\
\hline T4 (skin or chest wall involvement) & 0 & 0.00 & 3 & 0.62 & \\
\hline Regional lymph node metastasis & & & & & .026 \\
\hline No & 81 & 75.70 & 305 & 64.21 & \\
\hline N1 & 18 & 16.82 & 102 & 21.47 & \\
\hline N2 & 2 & 1.87 & 37 & 7.79 & \\
\hline N3 & 6 & 5.61 & 31 & 6.53 & \\
\hline Distant metastasis & & & & & NS \\
\hline Negative & 103 & 96.26 & 431 & 90.74 & \\
\hline Positive & 4 & 3.74 & 43 & 9.26 & \\
\hline AJCC TNM stage & & & & & NS \\
\hline I & 39 & 36.45 & 173 & 36.42 & \\
\hline II & 59 & 55.14 & 226 & 47.58 & \\
\hline III & 6 & 5.61 & 44 & 9.26 & \\
\hline IV & 3 & 2.80 & 32 & 6.74 & \\
\hline Mitotic figure & & & & & .036 \\
\hline Negative(<10/HPF) & 77 & 71.96 & 290 & 61.05 & \\
\hline Positive(>10/HPF) & 30 & 28.04 & 185 & 38.95 & \\
\hline ER & & & & & $<.0001$ \\
\hline Negative & 6 & 5.61 & 168 & 35.37 & \\
\hline Positive & 101 & 94.39 & 307 & 64.63 & \\
\hline PR & & & & & $<.0001$ \\
\hline Negative & 16 & 14.95 & 215 & 45.26 & \\
\hline Positive & 91 & 85.05 & 260 & 54.74 & \\
\hline HER2 & & & & & $<.0001$ \\
\hline Negative & 104 & 97.20 & 340 & 71.58 & \\
\hline Positive & 3 & 2.80 & 135 & 28.42 & \\
\hline
\end{tabular}

NEC indicates neuroendocrine carcinoma; NS, not significant; AJCC, American Joint Committee on Cancer; ER, estrogen receptor; PR, progesterone receptor; HER-2, human epidermal growth factor receptor 2.

test demonstrated statistical significance between these two groups $(\mathrm{P}=0.030)$.

Local recurrence. 4 of 107 NEC patients and 14 of 475 IDC, NOS patients had local recurrence. Log-rank test revealed a significantly higher rate of local recurrence in $\operatorname{NEC}(7.5 \%)$ than in IDC, $\mathrm{NOS}(2.8 \%)(\mathrm{P}=0.043)$.

Distant recurrence. The rate of distant recurrence in NEC patients was $5 \%$, while that in IDC, NOS was $8.3 \%$. Nevertheless the difference between the two groups in our hospital did not reach statistical significance $(\mathrm{P}=0.061)$. Distant recurrence occurs most commonly in bone and liver, as well as other less common sites, such as the lungs, pleura, contralateral breast, ribs, maxilla and mandible [16].
Prognostic factors of NEC. Analyses of prognostic factors are summarized in Table3. Kaplan-Meier showed that larger tumor size and TNM stage are inversely associated with OS and DRFS $(\mathrm{P}=0.003,<0.0001$, and $<0.0001,<0.0001$ respectively). Lymph node metastasis was no longer significant in predicting OS and DRFS.

Distant metastasis was significantly associated with poor OS and DRFS $(\mathrm{P}<0.0001,<0.0001$, respectively). In the NEC cohort, survival rate of patients with distant recurrence was $25 \%$, which was much lower than that of $95 \%$ in patients without distant recurrence. Further test of Cox regression revealed that it was a dependent prognostic factor for poor OS $(\mathrm{P}<0.0001)$. 
Table3. OS and DRFS of Patients With NEC of the Breast

\begin{tabular}{|c|c|c|c|c|c|c|c|c|}
\hline & \multicolumn{2}{|c|}{ OS } & \multirow{2}{*}{$\begin{array}{c}\text { Median OS, } \\
\text { mo }\end{array}$} & \multirow[t]{2}{*}{$\mathbf{P}$} & \multicolumn{2}{|c|}{ DRFS } & \multirow{2}{*}{$\begin{array}{c}\text { Median } \\
\text { DRFS, mo }\end{array}$} & \multirow[t]{2}{*}{$\mathbf{P}$} \\
\hline & $\begin{array}{c}\text { No. of } \\
\text { Patients at } \\
\text { Risk }\end{array}$ & $\begin{array}{c}\text { Survival } \\
\text { Rate, \% }\end{array}$ & & & $\begin{array}{c}\text { No. of } \\
\text { Patients at } \\
\text { Risk }\end{array}$ & $\begin{array}{c}\text { Survival } \\
\text { Rate, } \%\end{array}$ & & \\
\hline Age, $y$ & & & & NS & & & & NS \\
\hline$\leq 60$ & 5 & 89 & 25 & & 1 & 98 & 22.5 & \\
\hline$>60$ & 3 & 95 & 35 & & 2 & 97 & 21 & \\
\hline Menopausal status & & & & NS & & & & NS \\
\hline Premenopausal & 4 & 86 & 32 & & 2 & 93 & 23 & \\
\hline Postmenopausal & 4 & 95 & 24 & & 1 & 99 & 21 & \\
\hline $\mathrm{T}$ classification & & & & .003 & & & & $<.0001$ \\
\hline $\mathrm{T} 1$ & 2 & 96 & 32 & & 0 & 100 & 29 & \\
\hline $\mathrm{T} 2$ & 4 & 93 & 21 & & 1 & 98 & 18 & \\
\hline $\mathrm{T} 3$ & 2 & 60 & 14 & & 2 & 60 & 11 & \\
\hline $\mathrm{T} 4$ & -- & -- & -- & & -- & -- & -- & \\
\hline $\mathrm{N}$ classification & & & & NS & & & & NS \\
\hline No & 6 & 93 & 24 & & 2 & 98 & 21 & \\
\hline N1 & 0 & 100 & 21 & & 0 & 100 & 18 & \\
\hline $\mathrm{N} 2$ & 0 & 100 & 40 & & 0 & 100 & 37 & \\
\hline N3 & 2 & 67 & 32.5 & & 1 & 83 & 30 & \\
\hline M classification & & & & $<.0001$ & & & & $<.0001$ \\
\hline M0 & 5 & 95 & 24 & & 0 & 100 & 21 & \\
\hline M1 & 3 & 25 & 33.5 & & 3 & 25 & 25.5 & \\
\hline AJCC TNM stage & & & & $<.0001$ & & & & $<.0001$ \\
\hline I & 2 & 95 & 33 & & 0 & 100 & 30 & \\
\hline II & 2 & 97 & 21 & & 0 & 100 & 18 & \\
\hline III & 2 & 67 & 31.5 & & 1 & 83 & 29 & \\
\hline IV & 2 & 33 & 35 & & 2 & 33 & 21 & \\
\hline Mitotic figure & & & & NS & & & & NS \\
\hline 0 & 4 & 95 & 25 & & 1 & 99 & 23 & \\
\hline 1 & 4 & 87 & 21 & & 2 & 93 & 18 & \\
\hline ER & & & & NS & & & & NS \\
\hline 0 & 2 & 67 & 41.5 & & 1 & 83 & 38.5 & \\
\hline 1 & 6 & 94 & 24 & & 2 & 98 & 21 & \\
\hline PR & & & & .001 & & & & .004 \\
\hline 0 & 4 & 75 & 17.50 & & 2 & 88 & 16 & \\
\hline 1 & 4 & 96 & 25 & & 1 & 99 & 23 & \\
\hline HER-2 & & & & NS & & & & NS \\
\hline 0 & 8 & 92 & 17.5 & & 3 & 97 & 21 & \\
\hline 1 & 0 & 100 & 25 & & 0 & 100 & 42 & \\
\hline Sy & & & & NS & & & & NS \\
\hline 0 & 1 & 91 & 24 & & 0 & 100 & 21 & \\
\hline 1 & 7 & 93 & 45 & & 3 & 97 & 21 & \\
\hline CgA & & & & NS & & & & NS \\
\hline 0 & 5 & 89 & 24 & & 2 & 96 & 21 & \\
\hline 1 & 3 & 95 & 24 & & 1 & 98 & 21 & \\
\hline Ki67 & & & & .009 & & & & .019 \\
\hline 0 & 2 & 97 & 23.5 & & 0 & 100 & 22 & \\
\hline 1 & 6 & 85 & 25 & & 3 & 93 & 20.5 & \\
\hline
\end{tabular}

OS indicates overall survival; DRFS, distant recurrence-free survival; NEC, neuroendocrine carcinoma; NS, not significant; ER, estrogen receptor; PR, progesterone receptor; HER-2, human epidermal growth factor receptor 2; Sy, synaptophysin; CgA, chromogranin A; Ki67,proliferation marker.

Kaplan-Meier test also showed that PR is a significant positive prognostic factor for OS, DRFS, and LRFS in NEC patients $(\mathrm{P}=0.001,0.004,0.009$, respectively). Survival rate in patients with PR expression was 96\%, whereas in PR-negative patients, the number was $75 \%$. Moreover, Ki67 was inversely correlated with OS and DRFS in NEC patients $(\mathrm{P}=0.009,0.019$, respectively). The survival rate of Ki67-positive patients to Ki67-negative patients was $85 \%$ to $97 \%$. 


\section{Discussion}

Our study is the largest series of NEC of breast to date, and the only one conducted in Chinese patients to reveal the clinicopathological features and prognostic significance of NEC. Although NEC of the breast was first demonstrated by Feyrter and Hartmann in 1963 [1] and had been sporadically reported since then $[17,18,3]$, there was no consensus on the definition of NEC, including how many of the tumor cells need to show NE differentiation and whether NE differentiation should be based on morphology alone or in conjunction with immunohistochemical studies of NE markers until 2003 when WHO defined it as a distinct type of mammary carcinoma, with more than $50 \%$ of neoplastic cells expressing NE markers by immunohistochemistry [6].

In this study, we reveal that NEC of the breast is a distinct tumor that differs from IDC, NOS in various clinicalpathological features and outcomes. This result is consistent with the study conducted by Weigelt that neuroendocrine carcinomas of the breast are molecularly distinct from histological grade- and molecular subtype-matched invasive ductal carcinomas [19]. Hypothesis might be that NEC of the breast did not rise from preexisting endocrine cells, but rather expressed a potentially differentiated pathway within breast carcinomas $[20,21]$. Our data also support the earlier studies that NEC of the breast tended to be ER/PR positive and HER-2 negative [20, 21,22 , $24]$, and presented at an older age than IDC, NOS. Furthermore, our study indicates that NECs had less LN metastasis and mitotic figure. Unfortunately, up until now, there is no such study on the differences of LN metastasis and mitotic figure between NEC and IDC,NOS. Therefore, we assume that more studies may be needed to verify these results.

Our study also shows that NEC of the breast has a poorer overall survival (OS) and local recurrence-free survival (LRFS) rate. A recently conducted study revealed that apart from poorer OS and LRFS rate, NEC also had a higher rate of distant recurrence ${ }^{[22,23,24]}$. Three other studies on small number of NEC patients revealed it to have a better prognosis $[25,26]$. However, Sapino [27] and Makretsov [28] revealed that there was no significant difference in prognosis between NEC and IDC, NOS. We believe that the larger number of patients in our series and our strict case controls account for these differences.

Our study shows that several factors contribute to prognosis of NEC of the breast. Higher T classification, M classification, TNM stage are inversely relevant to OS, LRFS, DRFS. Such conclusions are not yet been reported in other studies. We also demonstrate that $\mathrm{PR}$ is a predictor for better prognosis and Ki67 a predictor for worse prognosis. This also applies to IDC,NOS $[29,30,31]$, which means that NEC of the breast have some similar biochemical characteristics with IDC,NOS. Although Sapino [7] suggested that ER was highly correlated with long overall survival, our data reveal no specific information on whether ER expression is correlated with prognosis of NEC. Yao [32] and Bofin [9] revealed neuroendorine differ- entiation in breast carcinoma to be associated with a higher grade of differentiation and a lower malignancy grade, whereas some other studies $[33,8,34]$ suggested that NE markers had no prognostic significance. In this paper, we demonstrate that $\mathrm{NE}$ differentiation is not statistically significant in predicting prognosis.

In summary, the results of this comparative study of 107 NEC of the breast and 475 IDC, NOS patients reveal that NEC is a rare mammary carcinoma with distinct clinicopathological features and outcomes. With an older age at presentation, NECs are more likely to be ER/PR positive and HER-2 negative, and have a higher propensity for local recurrence and poorer OS. We confirm the significant prognostic role of tumor size, distant metastasis, TNM stage, PR and Ki67 expression. Since most NECs of the breast at our hospital are treated with traditional therapies that we use on IDC, NOS patients, the findings of our study may suggest that endocrine therapy and individualized therapies can be a promising alternative for NEC patients. Further studies with larger case number and longer follow-up will be needed in future researches.

Acknowledgements: The authors would like to thank the current and previous fellows in the Department of Pathology at Hushan Hospital, Fudan University for technical assistance in immunohistochemical staining. We would also like to thank Mr Rong Fan for statistical assistance and Ms Guoguo Shang for photographic assistance.

\section{References}

[1] FEYRTER F, HARTMANN G On the carcinoid growth form of the carcinoma mammae, especially the carcinoma solidum (gelatinosum) mammae (article in German). Frankf Z Pathol 1963; 73: 24-39.

[2] MODLIN IM, SHAPIRO MD, KIDD M An analysis of rare carcinoid tumors: clarifying these clinical conundrums. World J Surg 205; 29: 92-101.

[3] GUNHAN-BILGEN I, ZEKIOGLU O, USTUN EE, MEMIS A, ERHAN Y Neuroendocrine differentiated breast carcinoma: imaging features correlated with clinical and histopathological findings. Eur Radiol 2003; 13: 788-793.

[4] PAPOTTI M, MACRI L, FINZI G, CAPELLA C, EUSEBI V et al. Neuroendocrine differentiation in carcinomas of the breast: a study of 51 cases. Semin Diagn Pathol 1989; 6: 174-188.

[5] VAN LAARTHOVEN HA, GRATAMA S, WERELDSMA JC Neuroendocrine carcinoid tumors of the breast: a variant of carcinoma with neuroendocrine differentiation. J Surg Oncol 1991; 46: 125-132. http://dx.doi.org/10.1002/ jso.2930460211

[6] TAVASSOLI FA, DEVILEE P Pathology and genetics. In: Tumors of the Breast and Female Genital Organs. WHO Classification of Tumors Series. Lyon, France: IARC Press; 2003: 32-34.

[7] AZZOPARDI JG, MURETTO P, GODDEERIS P, EUSEBI V, LAUWERYNS JM 'Carcinoid' tumours of the breast: the morphological spectrum of argyrophil carcinomas. 
Histopathology 1982;6:549-69. http://dx.doi.org/10.1111/ j.1365-2559.1982.tb02750.x

[8] CUBILLA AL, WOODRUFF JM Primary carcinoid tumor of the breast, A report of eight patients. Am J Surg Pathol 1977; 1: 283-92. http://dx.doi.org/10.1097/00000478-19771200000001

[9] FISHER ER, PALEKAR AS Solid and mucinous varieties of so-called mammary carcinoid tumors. Am J Clin Pathol 1979; 72: 909-16.

[10] RIGHI L, SAPINO A, MARCHIÒ C, PAPOTTI M, BUSSOLATI G Neuroendocrine differentiation in breast cancer: established facts and unsolved problems. Semin Diagn Pathol 2010; 27: 69-76. http://dx.doi.org/10.1053/ j.semdp.2009.12.003

[11] ROVERA F, MASCIOCCHI P, COGLITORE A, LA ROSA S, DIONIGI G et al. Neuroendocrine carcinomas of the breast. Int J Surg 2008; 6 Suppl 1: S113-5. http://dx.doi.org/10.1016/ j.ijsu.2008.12.007

[12] BIGOTTI G, COLI A, BUTTI A, DEL VECCHIO M, TARTAGLIONE R et al. Primary small cell neuroendocrine carcinoma of the breast. J Exp Clin Cancer Res. 2004; 23: 691-696.

[13] SHIN SJ, DELELLIS RA, ROSEN PP Small cell carcinoma of the breast-additional immunohistochemical studies. Am J Surg Pathol. 2001; 25: 831-832. http://dx.doi.org/10.1097/ 00000478-200106000-00023

[14] CHEANG MC, CHIA SK, VODUC D, GAO D, LEUNG S et al. Ki67 index, Her2 status, prognosis of patients with luminal B breast cancer. J Natl Cancer Inst 2009; 101: 736-750. http:// dx.doi.org/10.1093/jnci/djp082

[15] SINGLETARY SE, CONNOLLY JL Breast Cancer Staging. Working With the Sixth Edition of the AJCC Cancer Staging Manual. CA Cancer J Clin 2006; 56: 37-47.

[16] SALAMA AR, JHAM BC, PAPADIMITRIOU JC, SCHEPER MA Metastatic neuroendocrine carcinomas to the head and neck:report of 4 cases and review of the literature. OOOOE 2009; 108: 242-247.

[17] WADE PM, MILLS SE, READ M, CLOUND W, LAMBERT MJ et al. Small cell neuroendocrine (oat cell) carcinoma of the breast. Cancer 1983; 52: 121-125.

[18] RUBINI G, D’EREDITA G Tc-99m sestamibi and in-111 dtpa octreotide uptake in breast carcinoma with neurendocrine differentiation. Clin Nucl Med 2000; 25: 482-483. http://dx.doi. org/10.1097/00003072-200006000-00023

[19] WEIGELT B, GEYER FC, HORLINGS HM Mucinous and neuroendocrine breast carcinomas are transcriptionally distinct from invasive ductal carcinomas of no special type. Mod Pathol 2009; 22: 1401-1414. http://dx.doi.org/10.1038/ modpathol.2009.112

[20] MALUF HM, KOERNER FC Carcinomas of the breast with endocrine differentiation: a review. Virchows Arch 1994; 425: 449-457.

[21] CLAYTON F, ORDONEZ NG, SIBLEY RK, HANSSEN G Argyrophilic breast carcinomas. Evidence of lactational differentiation. Am J Surg Pathol 1982; 6: 323-333. http://dx.doi. org/10.1097/00000478-198206000-00005
[22] WEI B, DING T, XING Y, WEI W, TIAN Z et al. Invasive Neuroendocrine Carcinoma of the Breast A distinctive subtype of aggressive mammary carcinoma. Cancer 2010; 116: 4463-4473. http://dx.doi.org/10.1002/cncr.25352

[23] TANG F, WEI B, TIAN Z, GILCREASE MZ, HUO L et al. Invasive mammary carcinoma with neuroendocrine differentiation: histological features and diagnostic challenges. Histopathology 2011; 59: 106-115. http://dx.doi.org/10.1111/ j.1365-2559.2011.03880.x

[24] TIAN Z, WEI B, TANG F, WEI W, GILCREASE MZ et al. Prognostic significance of tumor grading and staging in mammary carcinomas with neuroendocrine differentiation. Hum Pathol 2011; 42: 1169-1177. http://dx.doi.org/10.1016/ j.humpath.2010.11.014

[25] ZEKIOGLU O, ERHAN Y, CIRIS M, BAYRAMOGLU H Neuroendocrine differentiated carcinomas of the breast: a distinct entity. Breast 2003; 12: 251-257.

[26] LOPEZ BE, ALONSO RM, BARRAZA G, VAZQUEZ MA, BERNADO L et al. Solid neuroendocrine breast carcinomas: incidence, clinico-pathological features and immunohistochemical profiling. Oncol Rep 2008; 20: 1369-1374.

[27] SAPINO A, RIGHI L, CASSONI P, PAPOTTI M, GUGLIOTTA $P$ et al. Expression of apocrine differentiation markers in neuroendocrine breast carcinomas of aged women. Mod Pathol 2001; 14: 768-776. http://dx.doi.org/10.1038/ modpathol.3880387

[28] MAKRETSOV N, GILKS CB, COLDMAN AJ, HAYES M, Huntsman D Tissue microarray analysis of neuroendocrine differentiation and its prognostic significance in breast cancer. Hum Pathol 2003; 34: 1001-1008. http://dx.doi.org/10.1053/ S0046-8177(03)00411-8

[29] WEIGEL MT, DOWSETT M. Current and emerging biomarkers in breast cancer: prognosis and prediction. Endocr Relat Cancer. 2010; 17(4): R245-62. http://dx.doi.org/10.1677/ERC10-0136

[30] MC CORMACK O, HARRISON M, KERIN MJ, MCCANN A Role of the progesterone receptor (PR) and the PR isoforms in breast cancer. Crit Rev Oncog. 2007; 13(4): 283-301. http:// dx.doi.org/10.1615/CritRevOncog.v13.i4.20

[31] YERUSHALMI R, WOODS R, RAVDIN PM, HAYES MM, GELMON KA Ki67 in breast cancer: prognostic and predictive potential. Lancet Oncol 2010; 11(2): 174-83. http://dx.doi. org/10.1016/S1470-2045(09)70262-1

[32] YAO GY, ZHOU JL, ZHAO ZS, RUAN J Biological characteristics of breast carcinomas with neuroendocrine cell differentiation. Chin Med J (Engl) 2004; 117: 1536-1540.

[33] SCOPSI L, ANDREOLA S, PILOTTI S, BUFALINO R, BALDINI MT et al. Mucinous Carcinomas of the breast a clinicopathological, histochemical, and immunocytochemical study with special reference to neuroendocrine differentiation. Am J Clin Pathol 1994; 18: 702-711.

[34] SAWAKI M, YOKOI K, NAGASAKA T, WATANABE R, KAGAWA C et al. Prognostic importance of neuroendocrine differentiation in Japanese breast cancer patients. Surg Today 2010; 40(9): 831-835. http://dx.doi.org/10.1007/s00595-0094179-2 